\title{
The Impact of Climate Modes on Summer Temperature and Precipitation of Darwin, Australia, 1870-2011
}

\author{
Cameron Hunter, Jacqueline Binyamin* \\ University of Winnipeg, Department of Geography, Winnipeg, Canada \\ Email: *J.binyamin@uwinnipeg.ca
}

Received August 23, 2012; revised September 25, 2012; accepted October 5, 2012

\begin{abstract}
Monthly mean summer (DJF) temperature and precipitation from Global Historical Climate Network (GHCN-V3) for the period of 1870-2011, are analyzed to assess the role of teleconnections on climate of Darwin, Australia. Indices of El Niño-Southern Oscillation (ENSO), Antarctic Oscillation (AAO), Pacific Decadal Oscillation (PDO), North Atlantic Oscillation (NAO), Arctic Oscillation (AO), and Pacific North American Oscillation (PNA) are extracted from monthly means and compared with climatic data of Darwin. Most of these climate modes are shown to have a strong influence on the monthly mean summer temperature and precipitation. ENSO is shown to have a positive relationship with the amount of precipitation received and a negative relationship with the temperature. Where an El Niño event produces warmer drier conditions and a La Niña event produces colder wetter conditions. The AAO is shown to cause cold and dry conditions during the positive phase and warm and wet conditions during the negative phase. The PDO is shown to cause El Niño like condition during the positive phase causing warmer, drier weather, and La Niña like conditions during the negative phase causing cooler, wetter weather. Through the analysis it is also shown that the NAO, AO, and PNA have little effect on the temperature and precipitation patterns of Darwin.
\end{abstract}

Keywords: Climate Modes; Teleconnections; Climate of Darwin; Climate Change; Climate Variability; ENSO; AAO; PDO

\section{Introduction}

Darwin, Australia latitude $12.4^{\circ}$ south, longitude $130.9^{\circ}$ east is located on Australia's northwestern coast. Monthly average temperature and total precipitation data for Darwin International Airport, which is approximately 3 $\mathrm{km}$ from the Indian Ocean and is $30 \mathrm{~m}$ above sea level are obtained from Global Historical Climate Network (GHCN-V3) for the period of 1870-2011.

Darwin receives an average of $1693 \mathrm{~mm}$ of precipitation yearly, with the distribution of precipitation being very seasonal. Most of Darwin's yearly total precipitation is received in the summer months (DJF), while Darwin receives nearly no precipitation in the winter months (JJA). Darwin's average annual temperature is $27.6^{\circ} \mathrm{C}$ and due to its proximity to the ocean does not fluctuate much throughout the year. The temperature ranges from approximately $29^{\circ} \mathrm{C}$ in summer to a low of $25.5^{\circ} \mathrm{C}$ in winter. The proximity to the ocean mediated Darwin's temperature, cooling the air during the summer months and warming the air during the winter months. This moderating effect causes Darwin's small temperature range.

This paper investigates the effect of six teleconnec-

"Corresponding author. tions on summer temperature and precipitation of Darwin. These teleconnections include El Niño-Southern Oscillation (ENSO), Antarctic Oscillation (AAO), Pacific De cadal Oscillation (PDO), North Atlantic Oscillation (NAO), Arctic Oscillation (AO), and Pacific North American Oscillation (PNA). Our study is important because little work has been done on the effect that climate modes have on Darwin's temperature and precipitation.

The ENSO is categorized by sea surface temperature and atmospheric pressure anomalies, and measured using the Southern Oscillation Index (SOI) which is the pressure difference between Tahiti, and Darwin. ENSO has the strongest effect on the climate of the South Pacific, causing below average rainfall amounts during El Niño and above average rainfall amounts during La Niña for Darwin $[1,2]$. Several studies have explored the precipitation variability over Darwin and across the Australian continent [3-5]. While others have explored ENSO's effect on the Australian continent [1,2,6-9].

The AAO is measured using the Antarctic Oscillation Index (AOI) which is the difference between the surface pressures at $40^{\circ} \mathrm{S}$ and $65^{\circ} \mathrm{S}$ [10]. The two phases of AAO, the positive phase and the negative phase, are classified by the strength of the subtropical high and the subpolar 
low. The positive phase shows a strengthening of the subtropical high and a deepening of the subpolar low, creating a greater than normal pressure difference between the two [11]. While the negative phase shows a weakening of the subtropical high and subpolar low, creating a weak pressure gradient [10]. The AAO has a strong effect on the location of the southern hemisphere midlatitudejet stream and through this affects the temperature and precipitation patterns throughout southern hemisphere $[4,10]$.

The PDO is a long-lived El Niño-like pattern of Pacific climate variability. Its events can persist for 20 - 30 years and have a strong effect on the climate of North America. Fluctuating sea surface temperatures (SSTs) in the central North Pacific and along the west coast of North America distinguishes the positive and negative phases of this climate mode. When the PDO is in its warm or positive phase, SSTs in the western coast of North America are relatively warm and central North Pacific SSTs are cooler and vice versa in the cool or negative phase causing a change in the temperature and precipitation patterns in these areas [12,13].

The NAO is the result of pressure differences between the Azores high and the Icelandic low [14,15]. NAO affects the northern hemisphere winter climates of eastern North America and Europe, and as well affects the position of the Atlantic storm track.

The AO is identified by the pressure difference between the polar high and the atmospheric low south of the pole [16]. The strong pressure gradient causes the circumpolar vortex to strengthen keeping the cold polar air north $[17,18]$. The strengthening of the circumpolar vortex causes mild weather throughout Europe and cold weather in Greenland and Newfoundland during the northern hemisphere winter. The weak polar vortex brings cold weather to Europe and the United States and warm weather to Greenland and Newfoundland during the northern hemisphere winter.

The PNA affects the climate of the northern hemisphere. It deals with the $700 \mathrm{mb}$ heights for the locations, Hawaii, the Aleutian Islands, southeastern United States and the Intermountain region of North America. The positive phase of the PNA shows higher than average heights over Hawaii and the Intermountain region of North American, while below average heights are recorded over the Aleutian Islands and the southeastern United States. The negative phase shows a reversal of the heights of these areas [19]. These height anomalies affect the position of the East Asian jet stream and in the positive phase produce above average temperature in the western United States and Canada and below average temperatures across the southern United States. PNA also affects the precipitation patterns of North America with the positive phase causing above average precipitantion on the Gulf of Alaska and below average precipitation for the Midwestern United States [19,20].

Section 2 describes temperature and precipitation results; and Section 3; summary and conclusions.

\section{Results and Discussion}

\subsection{Temperature}

Most of the Australian continent has experienced a warming trend in the past century, except for a region of cooling in the northwest [5]. Risbey [5] links this region of cooling to the increased amount of precipitation received in this area in the past century, and a greater permcentage of cloudy days blocking incoming solar radiation. Figure 1 shows that the temperature of Darwin has cooled approximately by $1.5^{\circ} \mathrm{C}$ over the past 129 years. While there is a large amount of year-to-year variation in the annual average temperature, there is clearly a strong cooling trend in the temperature. As Darwin is located along the northwest coast of Australia and as it is shown in Section 2.2., has seen an increase in the total precipitation received, this blocking of solar radiation by cloud cover could be one of the causes of the cooling temperature trend. Crowley [21] suggested that this cooling could be due to the northern hemisphere exporting cold water into the southern hemisphere. A seesaw effect is obnserved where warming in the northern hemisphere causes cold water from deep North Atlantic to circulate and surface in the southern hemisphere thereby cooling despite high $\mathrm{CO}_{2}$ levels [21].

Figure 2 shows again the trend of decreasing temperatures in Darwin, but it also reveals a period of colder than normal temperature. The period of 1942 to 2011 is shown to be on average $0.5^{\circ} \mathrm{C}$ cooler than would be expected by the trend. This period of cooling may be attributed to increased amounts of aerosols in the earth's atmosphere specifically sulfate aerosols created by volcanic activity, as well as anthropogenic activity. These

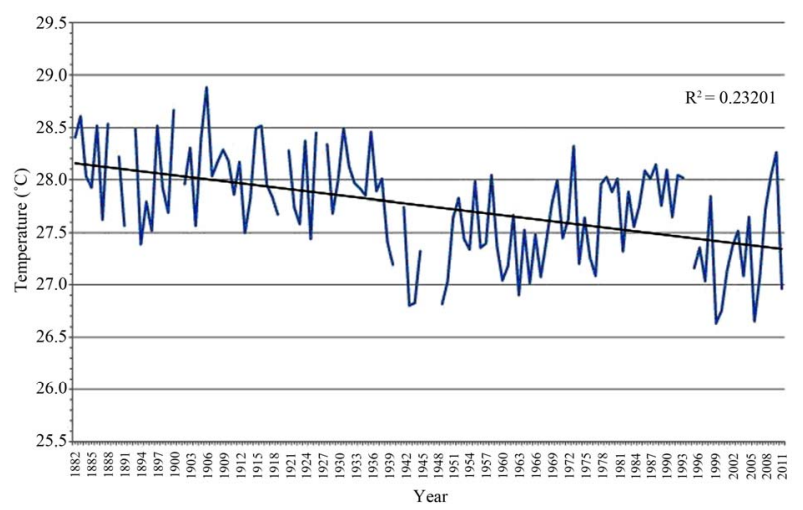

Figure 1. Average annual temperature $\left({ }^{\circ} \mathrm{C}\right)$ for Darwin, 1882-2011. Data are incomplete for some years and therefore are omitted. 


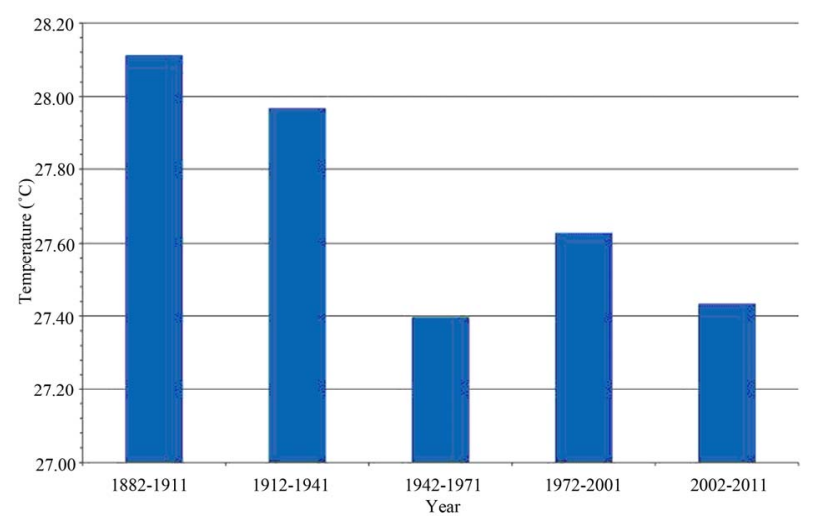

Figure 2. 30-year temperature $\left({ }^{\circ} \mathrm{C}\right.$ ) averages for Darwin, for the period 1882-2011.

aerosols reflect incoming solar radiation and reduce the amount of radiation reaching the surface, as well as acting as cloud condensation nuclei and increasing the cloud cover. Through these processes, sulfate aerosols decrease the temperature of the surface and lower atmosphere. We believe that sulfate aerosols are one of the possible causes of this anomalous cold period from 1942-2011.

The ENSO, AAO and the PDO show the strongest correlation with Darwin's temperature. ENSO shows a strong negative correlation with the summer temperature at Darwin. The correlation coefficient of -0.36 means strong negative values of the SOI will produce above average temperatures. Large negative SOI values represent strong El Niño events, these events seem to produce warm temperature anomalies, while positive SOI values represent La Niña event and produce cold anomalies at Darwin. Figure 3 shows this relationship between El Niño/La Niña events and the summer temperature in Darwin. The same relationship between temperature and SOI has also been recognized previously by Power et al. [6] and Suppiah [2]. This temperature trend could be due to the pressure systems above Darwin in summer during El Niño and La Niña events. During El Niño events a high-pressure system persists above Darwin, with air sinking and diverging at the surface. Therefore there is no uplift over Darwin and thus no clouds to reflect incoming solar radiation. During La Niña events the opposite occurs and a low-pressure system over Darwin causes converging air and uplift. Greater amounts of cloud over can be expected to reflect solar radiation increasing the local albedo and so less radiation is received at the surface and lower temperatures are experienced.

AAO also seems to have a strong effect on the average summer temperature of Darwin with a correlation coefficient of -0.42 . Figure 4 shows strong positive AAO events produces colder temperatures while negative events produces warmer temperatures. The shift of the southern hemisphere midlatitude jet stream by the change in the pressure gradient between the polar and the subtropical pressure centers produces bands of varying tem- perature and rainfall differences in the southern hemisphere, with a latitudinal band of cool temperatures falling on Australia during the positive phase and a latitudinal band of warmer temperatures during the negative phase [4].

PDO also shows a strong correlation with the average summer temperature of Darwin shown in Figure 5. The strong positive correlation coefficient of 0.37 shows PDO's strong effect on the summer temperatures of Darwin. The positive correlation means positive PDO events produce warm temperature anomalies while negative PDO events produce cold temperature anomalies. As well as affecting the atmosphere and oceans in the northern Pacific, the PDO also produces ENSO like conditions in the South Pacific. The PDO produces El Niño like conditions during the positive phase of the PDO, and La Niña like conditions during the negative phase of PDO [12]. The analogous ENSO conditions produced by the PDO explain the strong effect the PDO has on Darwin's temperature.

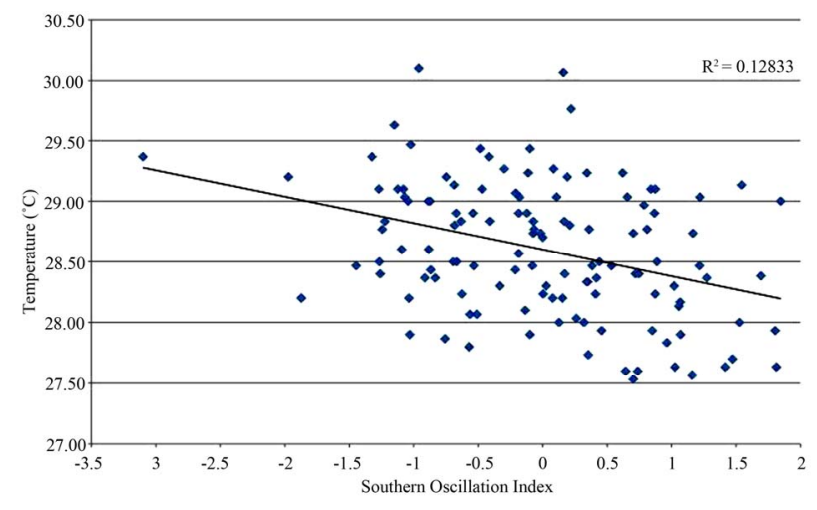

Figure 3. Correlation between average summer (DJF) Southern Oscillation index (SOI) and average summer temperature $\left({ }^{\circ} \mathrm{C}\right)$ for Darwin, 1882-2010. SOI data are from: http://www.cru.uea.ac.uk/cru/data/soi/soi.dat.

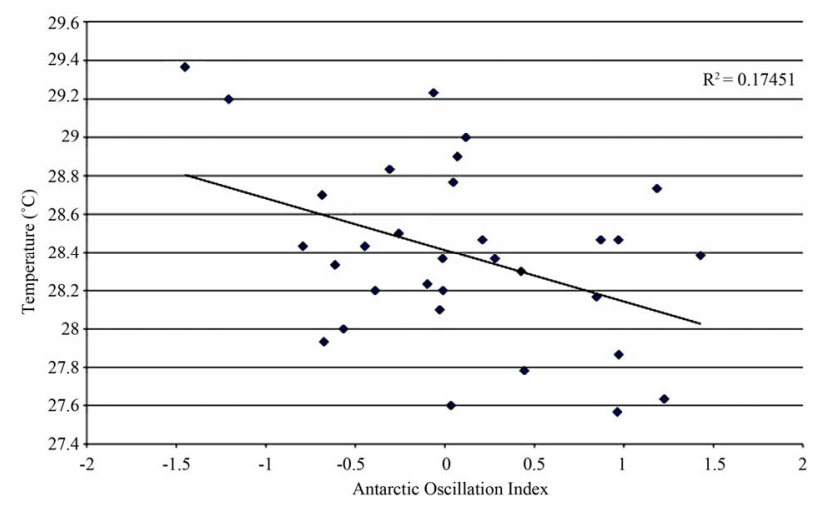

Figure 4. Correlation between average summer (DJF) Antarctic Oscillation (AAO) index and average summer temperature $\left({ }^{\circ} \mathrm{C}\right)$ for Darwin, 1980-2010. AAO Index data are from:

http://www.cpc.ncep.noaa.gov/products/precip/CWlink/dail y_ao_index/aao/monthly.aao.index.b79.current.ascii.table. 


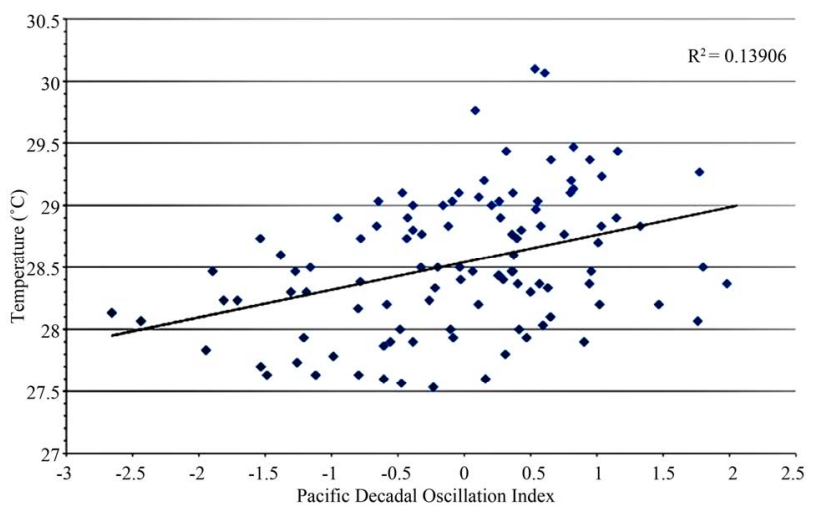

Figure 5. Correlation between summer (DJF) Pacific Decadal Oscillation (PDO) index and the average summer temperature $\left({ }^{\circ} \mathrm{C}\right)$ for Darwin, 1902-2010. PDO Index data are from: http://jisao.washington. edu/pdo/PDO.latest.

The NAO, AO, and PNA are shown to have little effect on the temperature of Darwin. As these three teleconnections affect the atmospheric and oceanic circulation in the northern hemisphere, their effect on Darwin if they have any, is too small to be discovered. If there is any effect on the climate of Darwin, it is likely masked by other interactions due to the large distance separating Darwin from the centers of action of these oscillation systems.

\subsection{Precipitation}

Darwin has experienced an increase in the yearly total precipitation received in the last 142 years (Figure 6). On average Darwin received $650 \mathrm{~mm}$ more precipitation in a year now than in 1870. The trend in precipitation at Darwin follows the trend of precipitation across all of Australia, with the coastal wet regions receiving more precipitation and the interior dry regions receiving less [5].

As with temperature the ENSO, AAO, and PDO all are shown to have strong effects on the yearly summer precipitation totals. Again AO, NAO and PNA have little effect on Darwin's precipitation. The correlation coefficient between summer averages of SOI and total summer precipitation for Darwin is 0.21 (Figure 7). The strong positive correlation means that La Niña events, (positive SOI values) causes greater than normal precipitation and El Niño events (negative SOI values) produces less precipitation than normal. These precipitation anomalies are due to the persistent high and low pressures above Darwin during La Niña and El Niño. During El Niño the anomalous high-pressure over Darwin causes divergence and sinking air, as there are few processes of up lift in this area, therefore, less precipitation is received. La Niña events have the opposite effect, anomalous low-pressure over Darwin produces lots of uplift and thus lots of precipitation in the area $[4,6,11]$. Many strong El Niño/La Niña events have caused large precipitation anomalies in
Darwin. Both the summers of 1982-1983, and 1997-1998 were strong El Niño events with summer average SOI values of -3.06 and -2.16 respectively; these years received $576 \mathrm{~mm}$, and $532 \mathrm{~mm}$ less than normal precipitation. The strong La Niña event in the summers of 19981999 had an average SOI value of 1.16, which re- corded $148 \mathrm{~mm}$ of precipitation more than normal (Figure 6).

The AAO has the strongest effect on the summer precipitation totals for Darwin. Figure 8 clearly shows the positive relationship between the AAO index and the total summer's precipitation values with a correlation coefficient of 0.4. The positive correlation between AAO index and summer precipitation means the positive phase of AAO will cause greater than normal precipitation values in Darwin, and the negative phase of AAO will cause less than normal precipitation values. The movement of the southern hemisphere midlatitude jet stream south in the positive phase produces a dry band between $30^{\circ} \mathrm{S}$ and $50^{\circ} \mathrm{S}$ and a wetter band between $20^{\circ} \mathrm{C}$ and $30^{\circ} \mathrm{S}$ [4]. Darwin (latitude $12.4^{\circ} \mathrm{S}$ ) is located nearest to the later band and obviously receives some residual effect of the wet band. While the negative phase of AAO cause a dry band between $20^{\circ} \mathrm{S}$ and $30^{\circ} \mathrm{S}$ and this must cause less precipitation in Darwin.

The PDO also shows a strong influence on the precipitation of Darwin. As stated above the PDO creates El Niño/La Niña conditions in the southern Pacific, as it affects the Northern Pacific [12]. The correlation coefficient of -0.21 shows that dry El Niño type conditions are produced by the positive phase of PDO and wet La Niña like conditions are produced during by the negative phase of PDO (Figure 9). The figure also shows the negative relationship between PDO and summer precipitation values.

\section{Summary and Conclusions}

Darwin has undergone a cooling of $1.5^{\circ} \mathrm{C}$ of its average

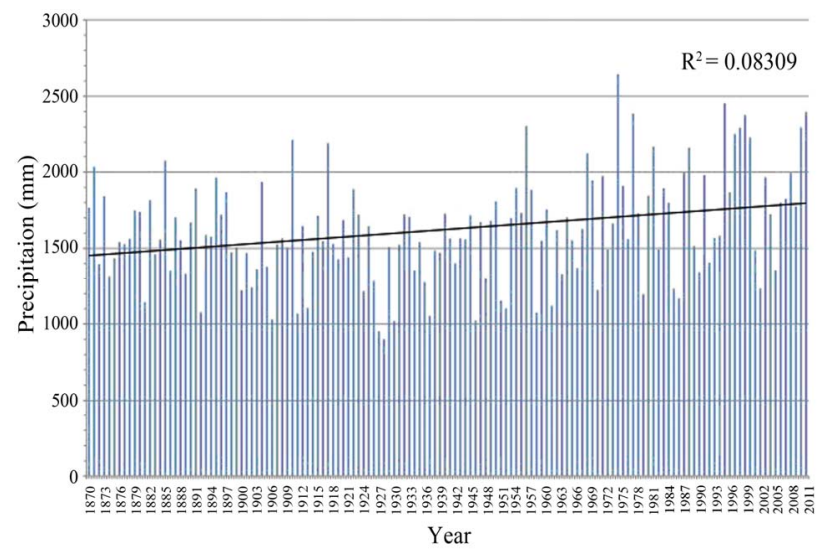

Figure 6. Total annual precipitation $(\mathrm{mm})$ received in Darwin, 1870-2011. 


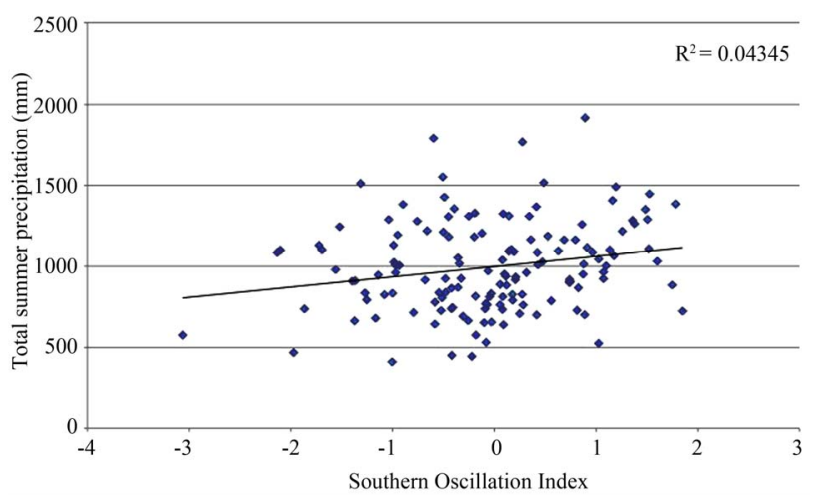

Figure 7. Correlation between the Southern Oscillation Index (SOI), and the total summer (DJF) precipitation for Darwin, 1871-2010. SOI data are from:

http://www.cru.uea.ac.uk/cru/data/soi/soi.dat.

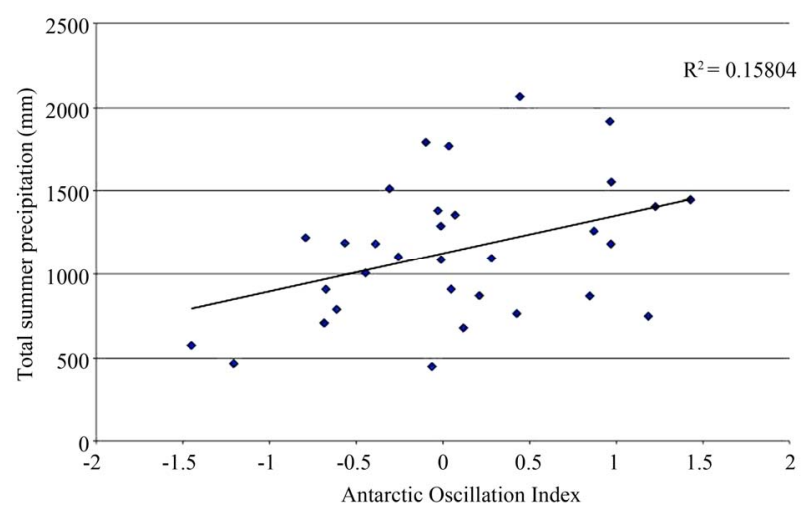

Figure 8. Correlation between Antarctic Oscillation (AAO) Index and the total summer (DJF) precipitation for Darwin, 1980-2011. AAO Index data are from:

http://www.cpc.ncep.noaa.gov/products/precip/CWlink/dail y_ao_index/aao/monthly.aao.index.b79.current.ascii.table.

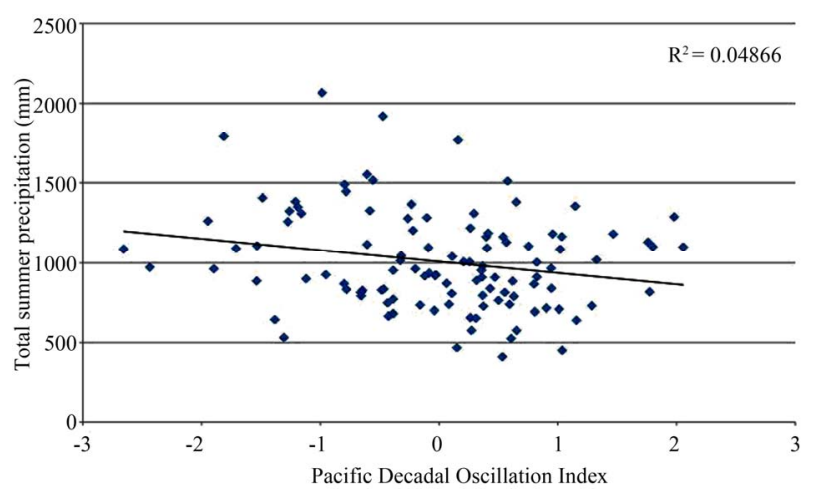

Figure 9. Correlation between the Pacific Decadal Oscillation (PDO) Index and the total summer (DJF) precipitation for Darwin, 1902-2011. PDO Index data are from: http://jisao.washington.edu/pdo/PDO.latest.

annual temperature during the period of 1882-2011. This cooling can be attributed to increased precipitation in the northwestern regions of Australia causing these areas to receive less solar radiation due to blocking of solar radiation by cloud cover. Another explanation of this cooling could be due to cold water from deep north Atlantic surfacing in the southern hemisphere and cooling the southern oceans. The atypical cool period from 1942-2011 could possibly be due to increased sulfate aerosols in the atmosphere, which reflect solar radiation. Sulfate aerosols also act as cloud condensation nuclei, increasing the cloud cover and reducing the amount of radiation reaching the surface leading to cooling of the surface and the lower atmosphere.

The ENSO, AAO and PDO have all been shown to have a large effect on Darwin's average summer temperature. The ENSO is shown to produce warmer conditions at Darwin during El Niño events and cooler condi tions during La Niña events. The AAO produces cold weather during the positive phase and warm weather during the negative phase. Unlike AAO the PDO' positive phase is shown to produce warm weather and the negative phase is shown to produce cooler weather at Darwin.

Precipitation in Darwin increased during the 18702011 period by an amount of $650 \mathrm{~mm}$. Also, ENSO, AAO and PDO are all observed to have a large effect on the summer precipitation in Darwin. El Niño events produce much dryer summers and La Niña events produce wetter summers. The low-pressure present during La Niña events causes convergence and precipitation over Darwin, while the high pressure present during El Niño events causes divergence and clear skies. The AAO is shown to cause drier summer weather during the negative phase and wetter summer weather during the positive phase. Finally the PDO causes Darwin to experience dry summer weather during the positive phase and wet summer weather during the negative phase.

Climate modes are shown to have a large effect on the Darwin's summer temperature and precipitation and have significantly changed its yearly average temperature and total precipitation in the past 140 years. A greater change in the Earth's climate will likely have an effect on the frequency and strength of the climate modes discussed and will thus greatly alter Darwin's climate as well as the climate of other locations. Future research is needed to understand the relationship between climate change and variability and the climate modes in order to be able to forecast the effect of climate change on other locations.

\section{REFERENCES}

[1] H. F. Diaz, M. P. Hoerling and J. K. Eischeid, "ENSO Variability, Teleconnections and Climate Change," International Journal of Climatology, Vol. 21, No. 15, 2001, pp. 1845-1862. doi:10.1002/joc.631

[2] R. Suppiah, “Trends in the Southern Oscillation Phe- 
nomenon and Australian Rainfall and Changes in Their Relationship,” International Journal of Climatology, Vol. 24, No. 3, 2004, pp. 269-290. doi:10.1002/joc.1001

[3] B. Meneghini, I. Simminds and I. N. Smith, “Association between Australian Rainfall and the Southern Annular Mode," International Journal of Climatology, Vol. 27, No. 1, 2007, pp. 109-121. doi:10.1002/joc.1370

[4] I. G. Watterson, "Components of Precipitation and Temperature anomalies and the Change Associated with the Modes of the Southern Hemisphere," International Journal of Climatology, Vol. 29, No. 6, 2009, pp. 809-827. doi:10.1002/joc.1772

[5] J. S. Risbey, "Dangerous Climate Change and Water Resources in Australia,” Regional Environmental Change, Vol. 11, Suppl. 1, 2011, pp. 190-203. doi:10.1007/s10113-010-0176-7

[6] S. Power, T. Casey, C. Follard, A. Colman and V. Mehta, "Inter-Decadal Modulation of the Impact of ENSO on Australia," Climate Dynamics, Vol. 15, No. 5, 1999, pp. 319-324. doi:10.1007/s003820050284

[7] L. D. Rotstayn, M. A. Collier, M.R. Dix, Y. Feng, H. B. Gordon, S. P. O’Farrell, I. N. Smith and J. Syktus, "Improved simulation of Australian Climate and ENSO-Related Rainfall Variability in a Global Climate Model with an Interactive Aerosol Treatment," International Journal of Climatology, Vol. 30, 2010, pp. 1067-1088.

[8] K. Wolter and M. S. Timlin, "El Niño/Southern Oscillation Behavior Since 1871 as Diagnosed in a Extended Multivariate ENSO Index (MEI.ext),” International Journal of Climatology, Vol. 31, No. 7, 2011, pp. 1047-1087. doi:10.1002/joc.2336

[9] K. S. Lui and J. C. Chan, "Interannual Variation of Southern Hemisphere Tropical Cyclone Activity and Seasonal Forecast of Tropical Cyclone in the Australian Region," International Journal of Climatology, Vol. 32, No. 2, 2012, pp. 190-202. doi:10.1002/joc.2259

[10] D. Gong and S. Wang, "Definition of Antarctic Oscillation Index,” Geophysical Research Letters, Vol. 26, No. 4, 1999, pp. 459-462. doi:10.1029/1999GL900003

[11] Intergovernmental Panel on Climate Change (IPCC), "Climate Change 2007: The Physical Science Basis," 2007.

http://www.ipcc.ch/publications_and_data/publications_i pcc_fourth_assessment_report_wg1_report_the_physical_ science_basis.htm

[12] N. J. Mantua and S. R. Hare, "The Pacific Decadal Oscil- lation,” Journal of Oceanography, Vol. 58, No. 1, 2002, pp. 35-44. doi:10.1023/A:1015820616384

[13] S. L. Lapp, J. St. Jacques, E. M. Barrow and D. J. Sauchyn, "GCM projections for the Pacific Decadal Oscillation under Greenhouse Forcing for the Early 21st Century,” International Journal of Climatology, Vol. 32, No. 9, 2011, pp. 1423-1442. doi:10.1002/joc.2364

[14] J. W. Hurrel and H. Van Loon, "Decadal Variation in Climate Associated with the North Atlantic Oscillation," Climate Change, Vol. 36, No. 3-4, 1997, pp. 301-326. doi:10.1023/A:1005314315270

[15] J. Marshall, Y. Kushnir, D. Battisti, P. Chang, A. Czaja, R. Dickson, J. Hurrel, M. McCartney, R. Saravanan and M. Visbeck, "North Atlantic Climate Variability: North Atlantic Climate Variability: Phenomena, Impacts and Mechanisms,” International Journal of Climatology, Vol. 21, No. 15, 2001, pp. 1863-1898. doi:10.1002/joc.693

[16] M. H. P. Ambaum, B. J. Hoskins and D. B. Stephenson, “Arctic Oscillation or North Atlantic Oscillation?” Journal of Climate, Vol. 14, No. 16, 2001, pp. 3495-3507. doi:10.1175/1520-0442(2001)014<3495:AOONAO >2.0. $\mathrm{CO} ; 2$

[17] D. W. J. Thompson and J. M. Wallace, "The Arctic Oscillation Signature in the Summertime Geopotential Height and Temperature Fields,” Geophysical Research Letters, Vol. 25, No. 9, 1998, pp. 1297-1300. doi:10.1029/98GL00950

[18] I. G. Rigor, J. M. Wallace and R. L. Colony, "Response of Sea Ice to the Arctic Oscillation,” Journal of Climate, Vol. 15, No. 18, 2002, pp. 2648-2663. doi:10.1175/1520-0442(2002)015<2648:ROSITT >2.0.C $\underline{\mathrm{O} ; 2}$

[19] NOAA Climate Prediction Center, "Pacific/ North America (PNA)," 2012 http://www.cpc.ncep.noaa.gov/data/ teledoc/pna.shtml.

[20] D. J. Leather, B. Yarnal and M. A. Palecki, “The Pacific/ North American Teleconnection Patter and United States Climate. Part I: Regional Temperature and Precipitation Associations,” Journal of Climate, Vol. 4, No. 5, 1991, pp. 517-528. doi:10.1175/1520-0442(1991)004<0517:TPATPA >2.0.C $\underline{\mathrm{O} ; 2}$

[21] T. J. Crowley, "North Atlantic Deep Water Cools the Southern Hemisphere,” Paleoceanography, Vol. 7, No. 4, 1992, pp. 489-497. doi:10.1029/92PA01058 